\title{
Chapter 13 \\ So What Do You Do? Experimenting with Space for Social Creativity
}

\author{
Ariane Berthoin Antal and Victor J. Friedman
}

\begin{abstract}
Direct experience comes from nature and man interacting with each other. In this interaction, human energy gathers, is released, dammed up, frustrated and victorious. There are rhythmic beats of want and fulfilment, pulses of doing and being withheld from doing.
\end{abstract}

(Dewey, 1934/2005, p. 1)

As John Dewey (1934/2005) observed "the first great consideration is that life goes on in an environment; not merely in it but because of it, through interaction with it" (p. 12, italics in original). It is puzzling that although organizational scholars may agree with him, they have not agreed on how social and physical space interact. Researchers who consider it problematic that "most previous research assumes that spatial orderings of things and people are merely part of the background" (Edenius \& Yakhlef, 2007, p. 207) have been exploring space in organizations from different angles. Some authors are very critical of the passive role assigned to space: "To picture space as a 'frame' or container with no other purpose than to preserve what has been put in it is an error displaying traces of Cartesian philosophy" (Kornberger \& Clegg, 2004, p. 1101). However, there is a risk that analysts attempting to redress the balance sometimes attribute such great powers to space as to anthropomorphize it and thereby relegate its inhabitants to the status of pawns of masterbuilders (e.g., Kornberger \& Clegg, 2004). Our contention is that a clear conceptualization of the relationship between physical and social space is critical for understanding the actions people undertake in their present setting and envisage for the future. Our

\footnotetext{
A. Berthoin Antal $(\bowtie)$

Research Group Science Policy Studies, WZB Berlin Social Science Center, Berlin, Germany e-mail: ariane.berthoin.antal@wzb.eu

V.J. Friedman

Department of Sociology and Anthropology/Department of Behavioral Sciences, Max Stern Academic College of Emek Yezreel, Jezreel Valley, Israel
} 
objective in this chapter is to deepen our understanding of the relationship between space and the generation of knowledge through and for action.

\section{Theoretical Framework}

Some work has been done in this direction (Baldry, 1999; Edenius \& Yakhlef, 2007; Ford \& Harding, 2004; Friedman, 2011; Kornberger \& Clegg, 2004; Meusburger, 2009; Taylor \& Spicer, 2007; Woodward \& Ellison, 2010). A review of the growing literature on space in organization studies found the field fragmented but identified three principal streams, each with interesting contributions and shortcomings (Taylor \& Spicer, 2007). In one stream scholars conceive of space in terms of distance and proximity between points and have convincingly demonstrated how space makes a difference for important issues at the micro-, meso-, and macrolevels. However, they are "unable to account for the ways in which actors attribute meaning and significance to a space ... [and] not able to explain the role which perceptions or experiences of distances and proximity play" (p. 329). In another stream researchers compensate for this weakness by focusing on the materialization of power-but it is questionable "whether all spaces are necessarily manifestations of power" (p. 332). Furthermore, such a focus implies a "systematic disregard of the ways that space may actually be the product of inhabitants' ongoing experience and understandings" (p. 333). Scholars in the third stream attend to this gap by exploring "how spaces are produced and manifest in the experiences of those who inhabit them" (p. 333). The inherent disadvantages are that power relations are overlooked and that the emphasis on perception undervalues the material, physical aspects of space. Logically, therefore, Taylor and Spicer argue for an integrated approach that addresses all three dimensions by building on the ideas of Lefebvre (1974/1991), who sought to bring together mental, physical, and social modalities of space (see also Ford and Harding 2004 , p. 817). Although we agree that an integrated approach is needed, this particular proposal does not take some essential concepts into account.

Strikingly absent from the organizational literature on space is the work on social space by two of the twentieth century's most influential, and nonconventional, social scientists, the psychologist Kurt Lewin (1936, 1948/1997, 1951/1997) and the sociologist Pierre Bourdieu (1985, 1989, 1993, 1998; Bourdieu \& Wacquant, 1992). Both placed social space as the cornerstone of their theoretical and methodological work, turning to the philosophical work of Ernst Cassirer (1923/1953, $1944,1961)$, who conceived of space in rather relative terms as the positional quality of the material world. Cassirer, Lewin, and Bourdieu adopted the view that there is no empty space, only spaces that are formed by and between objects, and they applied this concept to the creation of social reality rather than to the physical world. At the heart of social space is a relational logic of social reality, which focuses neither on the individual nor the group as the unit of analysis but rather on the processes through which individuals, in interaction with others, construct their social spaces and identities (Friedman, 2011). These interactions are causal loops that link the ways people bring their thinking and feeling into the world through action, to 
other people's responses generated by those actions, and back again to the ways those responses are interpreted and to the ways they shape what people think, feel, and do. Cassirer (1961) depicted with special eloquence the recursive movement between thinking, feeling, and acting in space as a process of creating and experiencing possibilities: "Human action is known only in its realization; only when it is realized are we aware of its living possibilities... [I]ndeed, its work is precisely that of seeking and creating ever new possibilities" (p. 37).

Social spaces take shape when these interactions between people are sustained and acquire patterns that differentiate them and give them distinctive configurations. Each configuration of social space can be characterized by its constituents, the positions they hold relative to each other, the "rules of the game" that govern interaction, and the shared meanings that hold the space together and facilitate sustained interaction (Friedman, 2011). Hence, social space is a creation of the mind, a construct that can be used to think relationally about the physical or the social world and thereby provide a means for making order out of any given set of elements. Both Lewin and Bourdieu applied these basic ideas to the study of society and culture at every level of aggregation.

A problem with the conceptualization of the construction of social space thus far is that it has not attended to the physical dimensions of the process: humans with bodies interacting in physical spaces that also include objects. We propose to integrate the physical environment in this construction process by seeing space and objects as being in relation with people rather than by allotting them a separate ontological status as containers that hold, and influence, social behavior. The relation is created by the multiple senses with which humans experience the physical environment. Whereas the importance of bodily ways of knowing has been obvious to artists and neuroscientists (Lehrer, 2007), organizational researchers misplaced corporeality for many years and have only recently begun to retrieve it by drawing on notions of aesthetics (Linstead \& Höpfl, 2000, p. 3). The literature review cited above noted the emergence of this work in their third strand, though too narrowly, so we mine it further in this chapter.

Scholars seeking to bring the body back into the picture point out that "although an organization is indeed a social and collective construct..., it is not an exclusively cognitive one but derives from the knowledge-creating faculties of all the human senses" (Strati, 2000, p. 13). The aesthetic approach to studying human behavior reveals the roles the body plays in reading a context, first to make sense of it because "one of the first things a newcomer to any organization has to learn is how to navigate within this new spatial environment" (Baldry, 1999, p. 535). The newcomer makes "a prima facie aesthetic judgment" (Hein, 1976, p. 149) in defining the relational composition of a situation. People use all their senses to seek cues to make sense of and orient their behavior, and when the interaction occurs in a built physical space they orient themselves to the fixed factors (the structure, the walls, and the floor) and the semifixed factors, such as furniture and other movable objects (Rapoport, 1982). The body thereby also participates in deciding and signaling to others which rules of the game to adopt for the situation at hand. Researchers have shown "how bodily practices produce discourse in the form of rules, routines, and procedures" (Edenius \& Yakhlef, 2007, p. 195). 
Connecting aesthetic approaches to the analysis of the construction of social space therefore enriches the understanding of the relational processes of generating shared meaning and agreeing on how to behave in the current situation. Furthermore, the aesthetic dimension of experience plays a role in defining the scope for future social space because it has the "capacity to animate actors' imaginations and actions" (Woodward \& Ellison, 2010, p. 46).

In this chapter we use this integrated relational conceptualization of social and physical space to analyze data from a series of action experiments we organized in 2009 in Israel. We invited people in small mixed groups to explore together how to envisage a future social space in the same setting. We consciously intensified attention to the aesthetic dimension of the process from the outset by choosing a fine-arts studio as the setting and by providing art materials for the participants to use there, sharing the assumption that "creative activity with portable, discrete objects allows an extension of potential space" (Woodward \& Ellison, 2010, p. 50). For this chapter we have decided to apply an aesthetic approach to the data analysis by focusing only on the visual documentation in order "to avoid committing the cognitive and rational error of ignoring the bodies of the people involved in the decision process and only considering their minds" (Strati, 2000, p. 20). Our objective is, therefore, to explore how much one can learn about processes of constructing current and future social space, in which physical relations are integrated, by including aesthetic dimensions of the experience in the analysis.

The next section of the chapter describes the context in which we conducted the action experiments. It is followed by an explanation of the methodology that was used to collect and analyze the data. We then present an analysis of the sessions, in which we identify different configurations that evolved during the interactions of the participants with one another and with the physical aspects of a studio. In the final section of the chapter, we present our conclusions about how to conceptualize and analyze social and physical space in an integrated manner and suggest next steps.

\section{Context: The Studio for Social Creativity}

The stimulus for carrying out this study was the development of the Studio for Social Creativity at the Max Stern Jezreel Valley College in Israel, a college created to bring higher education to Israel's northern periphery (Friedman \& Desivilya, 2010). This region is characterized by chronic socioeconomic underdevelopment and deep intergroup divisions, especially between Jews and Palestinian Arabs. ${ }^{1}$ Victor and several other faculty members at the college were interested in

\footnotetext{
${ }^{1}$ The Israeli population is composed of approximately $80 \%$ Jewish and $20 \%$ Palestinian Arab citizens. This Palestinian population should be distinguished from Palestinians who live in the Occupied Territories - the West Bank (Samaria and Judea) and Gaza-and are not Israeli citizens. The Arab citizens of Israel are termed by different people in various ways, such as Arabs, Israeli Arabs, and Palestinians. Each of these terms has a political implication.
} 


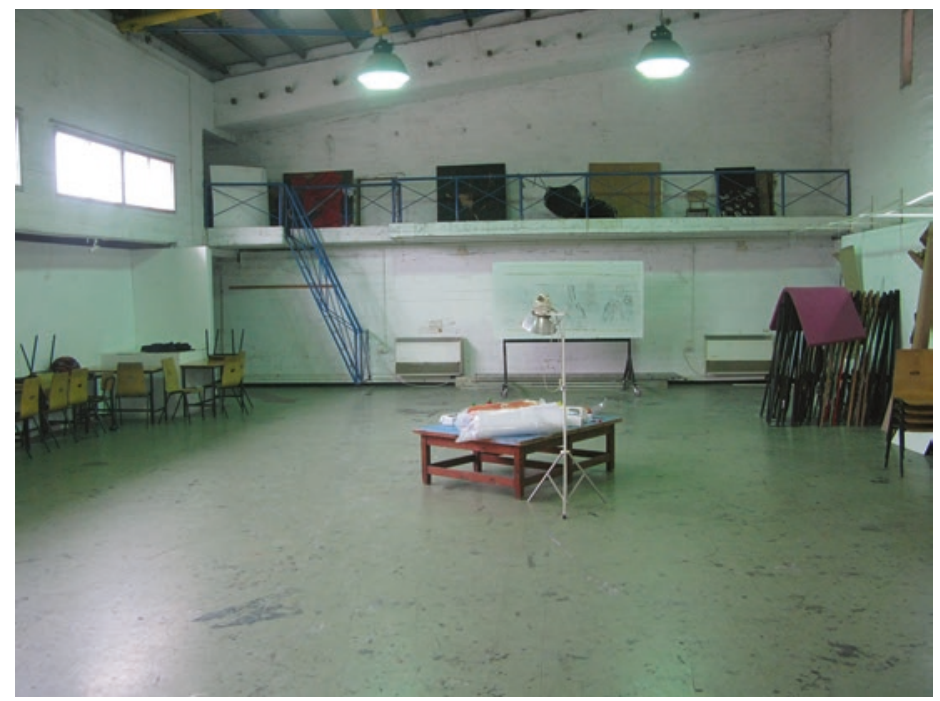

Fig. 13.1 The Studio for Social Creativity, Max Stern Jezreel Valley College, Israel (Photograph by the authors)

promoting a process in which people from the region could (a) bring up problems, ideas, and visions, (b) meet others with whom to learn and collaborate on issues of common concern, (c) work together to create innovative, viable projects and enterprises to meet human and economic needs, and (d) create and enact shared visions of regional development that promotes inclusiveness and interdependence rather than competition and divisiveness.

The original idea was to create a unique kind of incubator that would stimulate social entrepreneurship (Friedman \& Sharir, 2009), a process that would also include conflict engagement because the tensions in the region severely restrict the development of social capital needed for social entrepreneurship (Friedman \& Arieli, 2011; Friedman \& Desivilya, 2010). The idea of bringing in the arts to support the learning process was stimulated by Ariane's research on various forms of artistic interventions as triggers for organizational learning (Berthoin Antal, 2009, $2012,2013,2014$ ) and by our joint reflections on how to benefit from working with the arts in action research (Brydon-Miller, Berthoin Antal, Friedman, \& Gayá Wicks, 2011).

Serendipitously, Victor discovered on the college campus a little-used fine-arts studio, which had originally been the backstage area of a theater. He immediately experienced it as a space that offered powerful creative potential and decided that the studio metaphor as the environment in which to nurture innovative social thinking and action was much more appealing than the incubator metaphor, especially if people, practices, and products from the world of the arts could be integrated into these processes. The studio's large rectangular shape (approximately $16 \mathrm{~m}$ long and $12 \mathrm{~m}$ wide, or about $52^{\prime} \times 39^{\prime}$ ) offered an open, flexible space (see Fig. 13.1). A high 
ceiling contributed to the sense of spaciousness. The windows were set along the top of one of the long sides of the room, and the shorter sides each had a narrow balcony, accessible by narrow steep staircases. The stained linoleum floor showed signs of years of use. Water was available from a faucet in a washbasin.

Two critical questions needed to be clarified in order to launch the Studio for Social Creativity: What does it mean, in practice, to integrate processes of social entrepreneurship, conflict engagement, and the arts? How could the studio space be utilized to host and facilitate these processes? Having read the conceptual paper Victor had written with his colleague (Friedman \& Desivilya, 2010), Ariane suggested interrupting the writing process to actually engage with potential stakeholders-social entrepreneurs, experts on conflict, activists, artists, college faculty, and students-in the studio. Adapting Frye's (1964) succinct definition of imagination as "the power of constructing possible models of human experience" (p. 22), we observed that the discovery of the studio on campus offered the space for experimenting with imagination in practice. The stakeholders could be invited to participate in constructing possibilities for using the space for social innovation and for strengthening the link between the college and the community.

\section{Method: Action Experiments}

The first step was to identify people in the college and in the community who we thought would be interested in participating in what we called a series of action experiments. By this term we meant asking participants to develop and actively try out ideas together in a given space, recording the process, then analyzing it as a basis for ensuing steps. We use the term experiment in this chapter only to imply an exploratory learning-by-doing - trying something out in order to see what happens. We do not mean it here in the sense of a laboratory experiment, which implies both clear predictions about what should happen and a high degree of control so as to permit a clear linkage between cause and effect. In this case the action experiments entailed bringing mixed groups to explore what the Studio for Social Creativity could be in future. Victor approached each person personally and afterward sent a brief written description of the studio and the experiment. The text also explained that the sessions were to be filmed as a basis for development of and research on the studio. We organized five sessions in June 2009, distributing the 18 volunteers so that each session included participants with experience in social entrepreneurship, conflict engagement, and the arts, as well as both Jews and Palestinian Arabs, and men and women. ${ }^{2}$ The size of the groups varied from five to nine people, including the researchers. Although some of the participants knew each other, each mix included one or more people they did not know, so none of the sessions had groups

\footnotetext{
${ }^{2}$ We also held a sixth session but do not report on it here because it was quite different in format. It encompassed 60 students from the nursing program in the college, for whom the participants of Session 2 planned an intervention in the studio.
} 
whose members all had experience working together. In other words, each set of participants entered what was for them a new space with a new group and a new task.

The research team consisted of three people: the two authors and the cameraman, who was a drama student and the son of one of the authors. The members of the research team did not define themselves as facilitators or observers standing outside the experiment but rather interacted with the participants and took part in the thinking and action processes that unfolded. Victor participated fully in each session. Because Ariane did not speak Hebrew, the nature of her participation varied depending on whether the session was held in Hebrew (Sessions 2 and 4) or English (Sessions 1, 3, and 5). The cameraman filmed all of the sessions in the red-nose mask from the world of theater. He felt it would greatly enhance his ability to look on the action with curiosity and openness. By definition there was no language barrier for the cameraman: The Nose does not speak; it communicates with eyes and the rest of the body. As it turned out, the Nose also became part of the studio, signaling to participants as soon as they arrived that it was an unconventional place in which playfulness was allowed.

Our hope was that the participants would generate an output that would articulate their ideas in ways that could be observed, recorded, and shared with others. We also hoped that the participants would not only interact verbally but also use the room and art materials in some process of thinking and acting together. At the same time, we wanted to leave things as open as possible rather than impose a particular process on the participants. Our intention was to maximize the probability of generating newness. As Stark (2009) pointed out, "spaces of ambiguity" (p. 3) are important when the challenge is to generate newness by integrating knowledge from different domains. Prior to the experiment, we therefore defined for ourselves a number of principles that guided our behavior as conveners and researchers.

- Allow the participants to be as self-organizing as possible in their use of the space, their interactions with each other, their use of the resources, and the topics and issues they choose to discuss.

- Bring the participants' knowledge together on as equal a footing as possible. Although we were keenly interested in seeing how art might contribute to this process, we did not privilege the artists, nor any of the other participants, by explicitly attributing to them the status of experts, facilitators, or leaders.

- Set a clear time frame ( $2 \mathrm{~h}$ maximum). Aside from practical considerations, our research on artistic interventions sensitized us to the fact that time constraints can stimulate groups to reach higher levels of performance than the participants had previously considered achievable.

By choice, we wanted to allow each group to develop its own approach, so the general principle we followed was "trust the process" (McNiff, 1998).

The studio was sparsely furnished with art equipment: easels, stools, folding chairs, a platform (probably for a model), a spotlight, and a ladder. Each time we arrived in the studio these furnishings were already distributed around the room in no given order, and we did not arrange them for our participants. The walls were 
bare, except in one case, where balloons had been left hanging by the previous occupants. After each of our sessions, we removed whatever work had been produced so that it would not influence the participants in the subsequent session. Building on the artful-listening approach with which Ariane had been experimenting to support reflection and expression in groups, we bought materials (e.g., oil pastels, finger paints, plasticene, scissors, glue, a bell, a beach ball, and different kinds and sizes of paper) for the participants to play with during the sessions. Experiments in seminars Ariane had conducted had shown that people often reported that their listening was enhanced when they occupied their hands with other forms of expression. We placed the materials on the low platform, which was at the middle-front of the room. ${ }^{3}$ The participants were also invited to bring with them materials or tools they typically use in their practice. Only the musician in Session 1 took up this offer, bringing two musical instruments (an oud and a recorder).

We invited the participants in each session to meet in Victor's office and then walk together across campus to the studio so that they would begin the experiment together. The cameraman waited at the studio entrance to greet them as they arrived. Once everyone had entered the studio, we briefly explained the background to the experiment: the idea of the Studio for Social Creativity and how it had originated, the history of the space itself, the participants' task, and the guidelines. After this introduction we suggested that the participants explore the space for themselves, encouraging them to take the initiative and engage in the task without our guidance.

\section{Data Analysis}

We have undertaken several modes of analysis of the action-experiment sessions in the studio since conducting them in 2009. The first mode was simultaneous with the process - we discussed each experience intensely together and with the cameraman, exchanging thoughts and feelings about what was surprising, disappointing, or delighting us. The second was a preliminary review of the results based on transcripts we made of the recorded material, which we presented at a conference a month later (Berthoin Antal \& Friedman, 2009). As interesting as that material was, however, we soon realized that we, like other colleagues, had "fallen prey to the dominant approach to studying organization, by relying on discursive material" (Edenius \& Yakhlef, 2007, p. 209). We had in our hands the pictorial material those colleagues yearned for after the fact, but we had focused on the written words we had typed up! We therefore decided to write this chapter based entirely on what we could see happening in the film material. After considering different methods of analyzing these data, we decided to apply a grounded-theory approach (Glaser \& Strauss, 1967) rather than use a formal coding system derived from existing theories

\footnotetext{
${ }^{3}$ Having observed in the first session that the act of unpacking the materials might have been a barrier to using them, we took them out of their packaging as of the second session, spreading out the oil pastels and paint bottles on the platform to make them more easily available.
} 
on group dynamics or collective creativity processes that would restrict our vision to existing categories. More than a year after the experiences in the studio, we revisited the films and turned off the audio track, noting down separately what we saw people doing in the physical space-when and for how long they engaged with each other and with the fixed or semifixed physical aspects of the studio. We then compared our individual observations, jointly checking the film material again when we found we had noticed things differently. It is from this iterative process that we gained fresh insights into the integrated process of constructing social and physical space.

In the account that follows we rely as much as possible on these observations and provide visual illustrations from the video recording. Although we disciplined ourselves to base our analysis on the film material, it is difficult to exclude additional knowledge from our analysis completely, for we had jointly designed and experienced all the sessions. We include some details that are not based on the visible evidence when we feel it would be essential for the reader's understanding.

\section{Configurations in Spaces of Social Creativity}

Each of the sessions was unique in the ideas or works the participants came up with and in the ways they produced those outcomes. In observing the video recordings of the five sessions, however, we noticed patterns, or configurations, of organization and behavior. We use the term configuration in four senses: (a) the participants' positions in the room and relative to each other during a specific time period, (b) the observable interactions of the participants among each other and with materials in the room, (c) the observable application of behavioral rules, and (d) the creation of shared meaning (to the extent that it can be inferred from the group's observable behavior and outputs).

To illustrate these configurations and make inferences from them about the use of space for bringing together different kinds of knowledge to generate creative action, we first analyze in depth the pattern of configurations formed by participants in one of the sessions, Session 2. We then relate this pattern to those formed by participants in other sessions. We have chosen this session for presenting our analysis because it is representative in terms of the number and types of configurations and because the entire session is available on video recordings (parts of this material of two other sessions were corrupted, so we can analyze only their soundtracks).

\section{Looking Closely at a Sample Session}

As in all of the sessions, the participants in Session 2 were asked to think about how they would use this space to combine processes of social entrepreneurship, conflict engagement, and the arts in ways that would connect the college with the community and contribute to regional development. However, this session was unique 
Table 13.1 The nine participants in Session 2 of the action experiment at Max Stern Yezreel Valley College in Israel

\begin{tabular}{|c|c|}
\hline Description of participant & Reference in text \\
\hline Lecturer in the college nursing faculty, Jewish woman anthropologist & Lecturer \\
\hline \multirow{2}{*}{$\begin{array}{l}\text { Two Palestinian Arab women students participating in workshop on } \\
\text { social entrepreneurship }\end{array}$} & Student 1 \\
\hline & Student 2 \\
\hline $\begin{array}{l}\text { Jewish woman student participant in workshop on social } \\
\text { entrepreneurship }\end{array}$ & Student 3 \\
\hline $\begin{array}{l}\text { Teaching assistant in a social entrepreneurship practicum, Palestinian } \\
\text { Arab woman graduate of the college }\end{array}$ & Teaching assistant \\
\hline Jewish woman artist & Artist \\
\hline Action researcher, faculty member of the college, Jewish man & Researcher 1 \\
\hline $\begin{array}{l}\text { Senior researcher in a German research institute, French-American } \\
\text { woman }\end{array}$ & Researcher 2 \\
\hline Drama student filming the session, French-American man & Cameraman \\
\hline
\end{tabular}

Table 13.2 Session 2 of the action experiment at Max Stern Yezreel Valley College in Israel

\begin{tabular}{llc}
\hline Sequence & Configuration & Duration (in min.) \\
\hline 1 & Orientation & 15 \\
2 & Meeting mode & 19 \\
3 & Expansion & 25 \\
4 & Creation & 10 \\
5 & Reflection & 8 \\
6 & Exhibition & 3 \\
7 & Rehearsal & 20 \\
\hline
\end{tabular}

because it centered on meeting an immediate need on campus for a defined target group. A class of approximately 60 nursing students, half of them Jewish and half Palestinian Arab had requested support in engaging in a real conflict they were experiencing in class. The head of the nursing program had asked Victor and a member of the nursing faculty who taught anthropology to these students whether they could help the group address the issues (see also Arieli, Friedman, \& Knayzev, 2012). The two faculty members agreed to take on the challenge and decided to use a session in the studio to design it. Victor offered three students from his social entrepreneurship course the opportunity to work on the project with him as their practical assignment for the course, and he asked one of the teaching assistants in the social entrepreneurship course to help as well. The artist chosen for this session came on the recommendation of one of the students from the social entrepreneurship course. Table 13.1 provides an overview of the nine participants in Session 2.

Session 2 lasted 100 min, during which time the participants formed seven configurations in the studio space (see Table 13.2). The session was entirely in Hebrew because the students, the teaching assistant, and the artist were not comfortable using English. Researcher 2, therefore, did not speak in the session; she listened and observed but could not understand exactly what was said. 


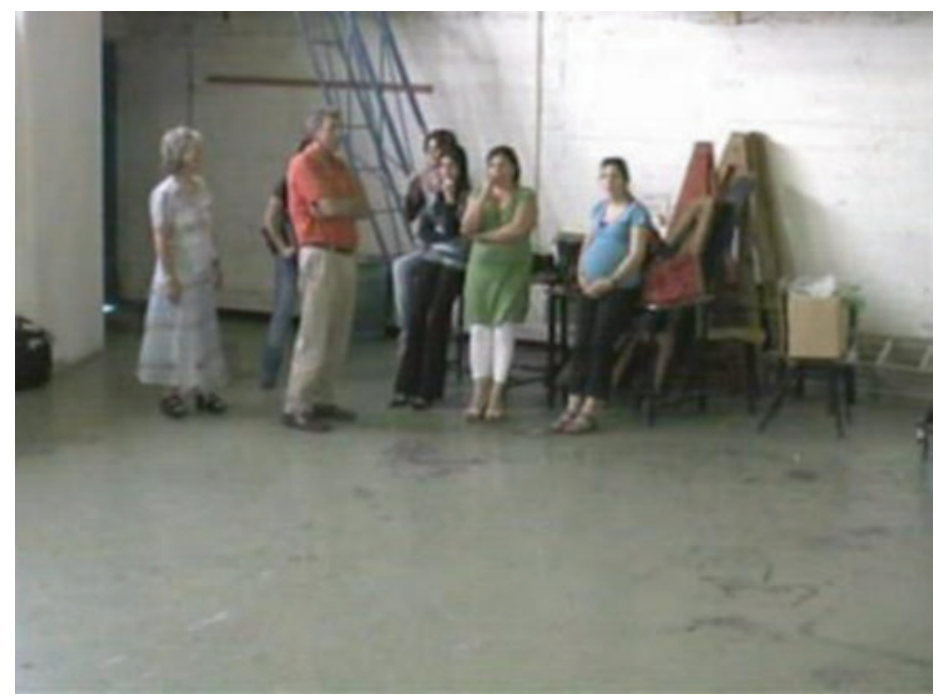

Fig. 13.2 Orientation configuration, Session 2 of the action experiment in the Studio for Social Creativity (Photograph by the authors)

The first configuration, Orientation, formed as soon as the participants entered the studio. As visible in Fig. 13.2, the participants bunched closely at the entrance to the studio (the door is invisible just to the left). Three of the participants leaned against a table, one sat on a table, and three stood (the teaching assistant had not yet arrived). At least three of the participants looked outwards into the studio space, getting a sense of the room itself. A few minutes into this configuration the video showed that the participants turned toward each other, talking, listening, gesturing, and looking at a document. ${ }^{4}$

In the Orientation configuration, the participants were acquiring a sense of both the space and their task in the session. Researcher 1 and the artist did most of the talking. To the extent that the participants explored the space, it was only with their eyes. The students, in particular, appeared pensive and uncomfortable with the size of the space and the uncertainty of the task itself.

The shift to a new configuration occurred a quarter of an hour into the session, shortly after the lecturer arrived. She briefly observed the situation, then found chairs, which student 3 helped her arrange in a semicircle in front of the table at which the participants were huddling. The positioning of the chairs caused a change in the positioning of the participants. Those who had been standing in front of the table sat down, facing the others, who were sitting or leaning on the table (see Fig. 13.3).

\footnotetext{
${ }^{4}$ In preparation for the intervention, the students in the nursing course had been asked to respond to a questionnaire asking them to define the kind of atmosphere they would like to create in their class, why this kind of atmosphere was important to them, and what concrete steps should be taken to create it. Researchers 1 and 3, together with the students from the course on social entrepreneurship, had analyzed the responses prior to Session 2 so as to provide a resource to the planning team.
} 


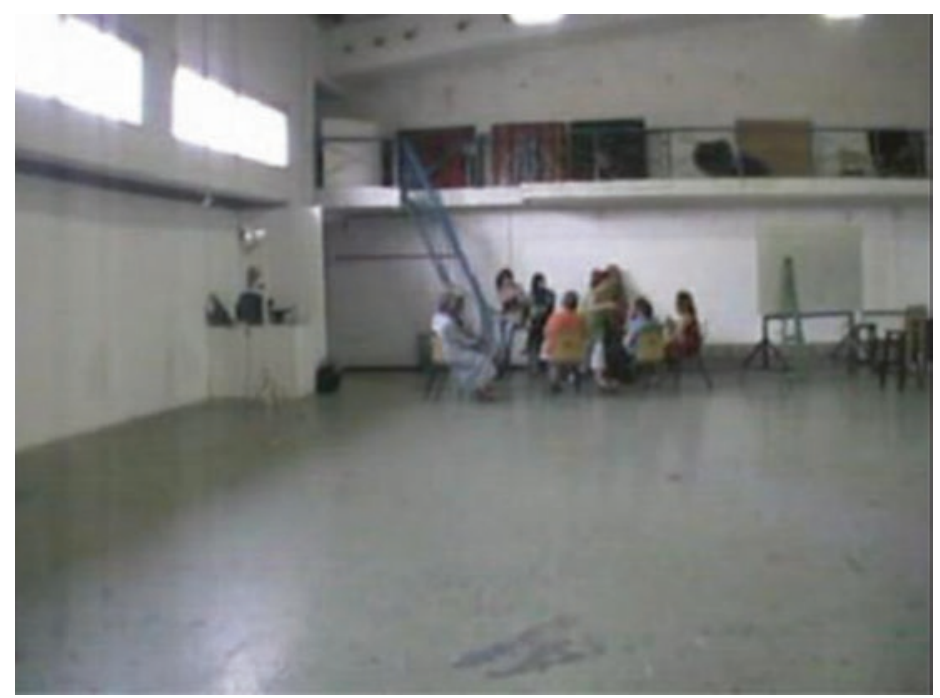

Fig. 13.3 Meeting-mode configuration, Session 2 of the action experiment in the Studio for Social Creativity (Photograph by the authors)

The new physical arrangement signaled to the participants that they were in a meeting, hence our choice of the name Meeting Mode for this configuration. The participants looked more comfortable with the situation, into which they could bring the known rules of behavior for meetings. More of the participants spoke during this configuration than during the Orientation.

Although there was a change in the organization and physical positioning of the participants in the Meeting Mode, there was almost no change in the group's location in the room. Figure 13.3 shows that the members of the group remained closely clustered next to the door through which they had entered the studio. Researcher 2 attempted to direct attention to the availability of larger space and the art materials by walking to front-center of the room, where the art materials were located on a low platform. She began finger-painting on a large piece of flipchart paper, capturing words she picked up from the conversation. However, the other participants did not appear to pay any attention to this attempt at modeling. The ineffectiveness of this attempt may be related to the language barrier that led researcher 2 to hover around the group but never actually join in the planning process throughout the session.

The next configuration, which we termed Expansion, began after 19 min (see Fig. 13.4). Researcher 1 stood up and walked toward the middle of the room, followed quickly by the teaching assistant. The other participants began to move slowly across the room toward the art materials, with the lecturer joining them after a conversation with students 1 and 2 .

Researcher 2 stopped finger-painting and picked up her sheet of flipchart paper from the pile on the platform so that others could take paper. The artist bent down 


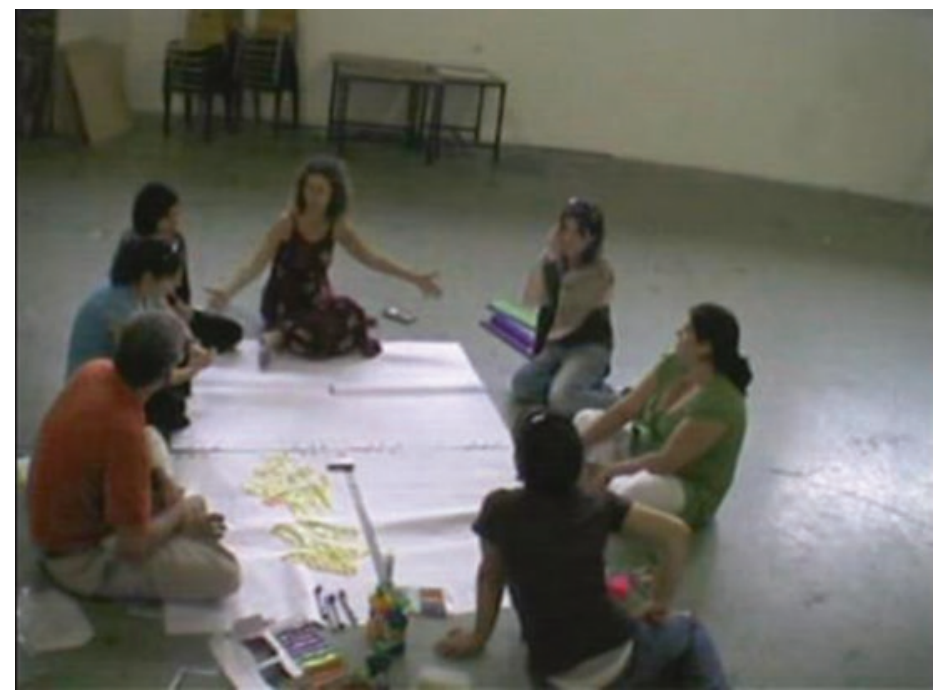

Fig. 13.4 Expansion configuration, Session 2 of the action experiment in the Studio for Social Creativity (Photograph by the authors)

and began picking up sheets of flipchart paper, spreading them on the floor in the middle of the room. Some of the participants began to look at, pick up, inspect, and handle the materials. The artist sat down on the floor, followed by researcher 1 , the lecturer, and then the students and the teaching assistant. Researcher 2 carried colors, paints, clay, and other materials from the platform to various points near the group.

We called this configuration Expansion because the participants pushed back the boundaries of the space they had created for themselves. Before sitting down, the artist had taken off her shoes, and the others followed suit, signaling a shift to less formal rules of behavior in the group's new space. The video recording of Session 2 shows the participants talking in a more relaxed way than in the previous two configurations and occasionally laughing. The lecturer began writing with a marker on the paper, researcher 1 played with finger-paints, and the teaching assistant also began to draw. The Expansion configuration involved exploration and the opening up of new possibilities for the use of the physical space, the materials, behaviors, and ways participants related to each other. Laughter broke out when researcher 1 withdrew an offer he had made on a piece of paper for the group to focus on. Observing the video material, we think that this moment marks another shift in the rules of behavior because the agenda-setting power of the most senior participant and convener of the session in the studio was visibly called into question. The lecturer then began to lead a discussion, looking at the other participants and inviting them to express themselves. It lasted for $25 \mathrm{~min}$, the lengthiest of all the configurations in Session 2. 


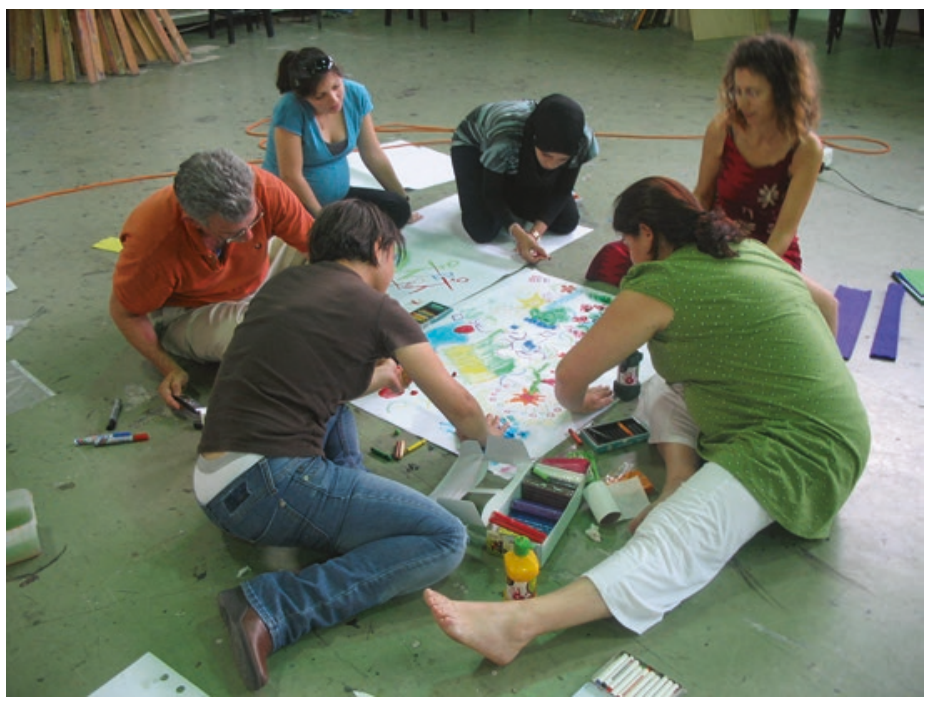

Fig. 13.5 Creation configuration, Session 2 of the action experiment in the Studio for Social Creativity (Photograph by the authors)

There was a sudden transition to a new configuration in which the participants began drawing or painting on two shared sheets of paper. Everyone was leaning forward, and there was an appearance of great intensity. We term this configuration Creation (see Fig. 13.5) because a relatively cohesive group took shape and created a collective work. ${ }^{5}$ During this Configuration the group appeared to be comfortable behaving as artists, each individual concentrating on aesthetic expression.

After $10 \mathrm{~min}$ of the intense Creation configuration, the participants of Session 2 stopped drawing on the paper and leaned back, looked at what they had done, and began talking again. We called this the Reflection configuration (see Fig. 13.6). The rules of the game were no longer the same as in the previous configurations that had been dominated by talking: The participants pointed to elements on the paper, asked questions, and invited others to speak. No one speaker dominated, and the material that lay in the middle of the room played a significant role. The participants remained in the same physical location and arrangement, and there was no movement through the space of the studio. However, by leaning back to consider the physical expression of their shared thinking, they appear to have expanded the space they inhabited together at that moment.

The Reflection configuration lasted $8 \mathrm{~min}$, at which point all of the participants stood up, took the picture they had created, hung it on the front wall of the studio, and stepped back to look at it. We termed this configuration Exhibition (see Fig. 13.7) because it was as though the participants had transformed part of the

\footnotetext{
${ }^{5}$ The audio material reveals that at this point the group had just decided to experiment together with how they would actually envisage the intervention with the class of 60 students.
} 


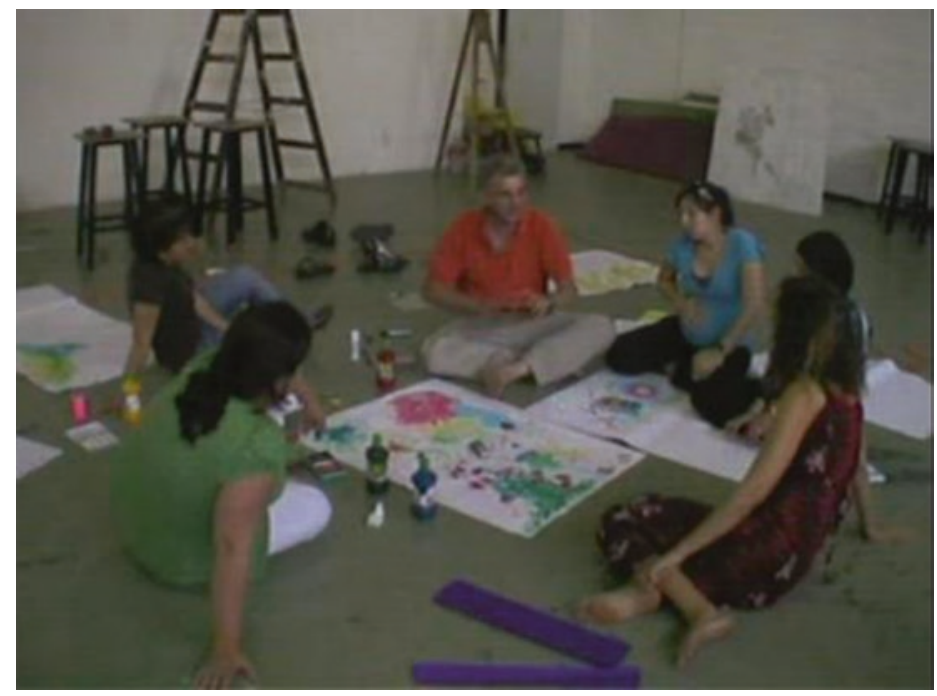

Fig. 13.6 Reflection configuration, Session 2 of the action experiment in the Studio for Social Creativity (Photograph by the authors)

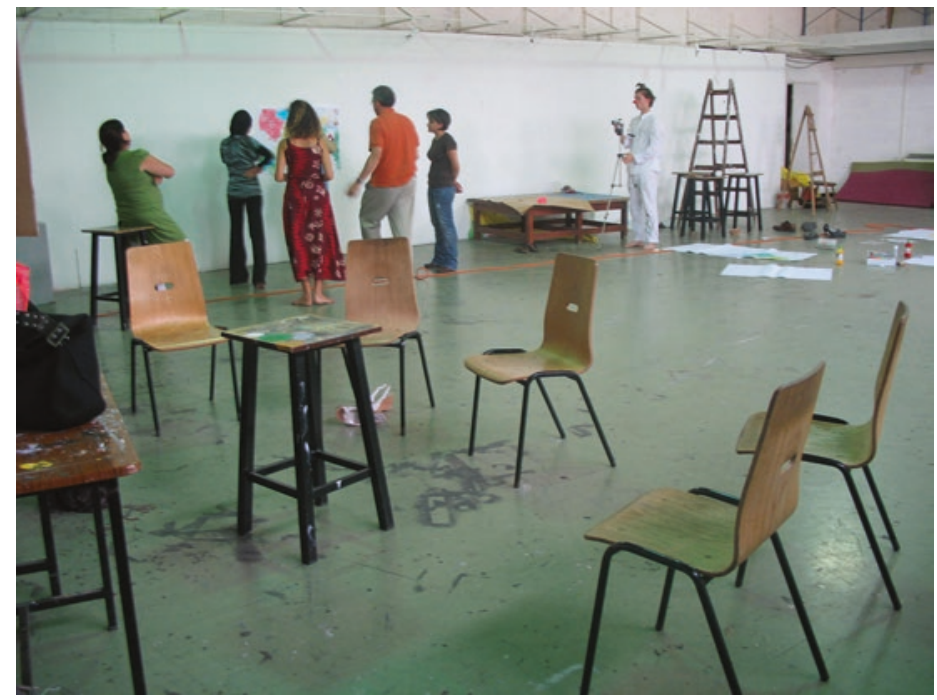

Fig. 13.7 Exhibition configuration, Session 2 of the action experiment in the Studio for Social Creativity (Photograph by the authors) 


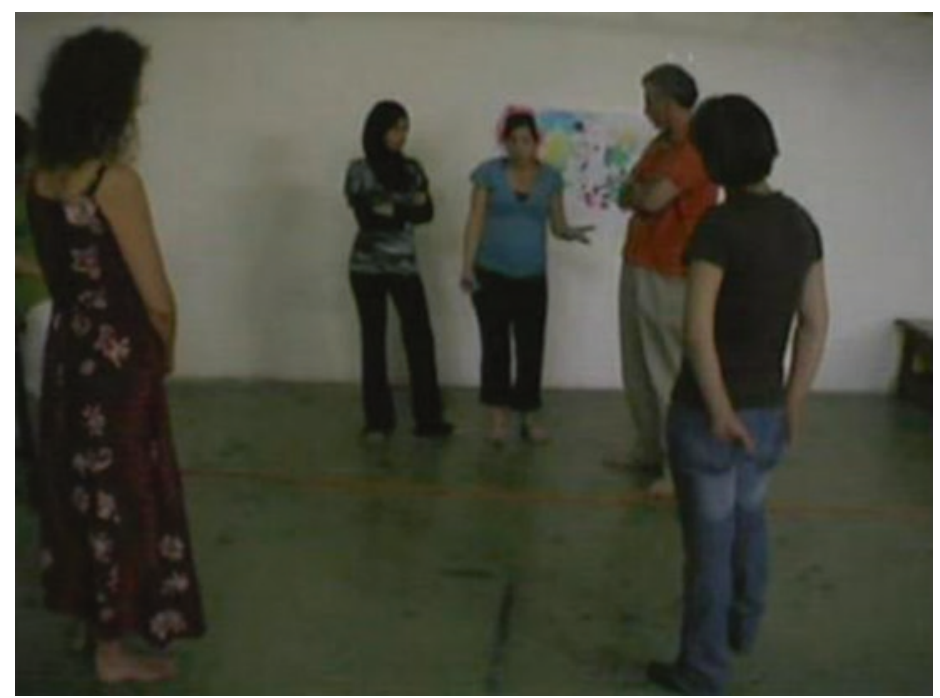

Fig. 13.8 Rehearsal configuration, Session 2 of the action experiment in the Studio for Social Creativity (Photograph by the authors)

studio into an exhibition space, displaying their work as artists usually do. In this configuration the participants not only moved to a different part of the studio and used wall space for the first time, they behaved differently from all previous constellations by arranging themselves as though they were in a gallery, standing opposite a picture, observing it, and commenting to cospectators.

Figure 13.7 also documents how the participants traversed and utilized various parts of the studio space at different times. Traces of earlier configurations remain: the chairs from the Meeting Mode in the foreground, near the entrance to the studio; and the papers on the floor in the front-center of the room.

The Exhibition configuration in Session 2 lasted for only $3 \mathrm{~min}$, at which point the participants re-formed into a kind of a loose circle with the picture to their backs and began talking and moving around, using a much larger part of the room. We termed this new arrangement the Rehearsal configuration (Fig. 13.8) because the video recording shows the participants physically acting something out to each other and commenting after each performance.

The audio file documents that the participants were talking about and trying out how to apply what they had learned from this process to the following week's planned session with the 60 nursing students. The Rehearsal implied expanding the space of the participants in several ways: They moved around a larger portion of the studio while acting out their presentations, they extended their space into the future, and they related to the entire studio space as they envisioned the way 60 nursing students could use it in the upcoming intervention. 
Rehearsal was the final configuration we observed in this session. It lasted for 20 min-until the time for Session 2 ran out - at which point the group broke up, some participants rushed away, and others began cleaning up while talking.

\section{Comparative Analysis Across Sessions}

Having looked at Session 2 in some depth, we now compare it with the other sessions to specify the configurations and their various forms. There was a different group of participants in each session, but they were all given the same basic task. Each group used the space and the materials in a different way and came up with very different insights and products. Nevertheless, most of the configurations we observed in Session 2 recurred in the other sessions as well, though not always in the same order. A comparative analysis permits us to hypothesize that-

1. there are definable configurations of participants' positions and interactions among each other and with materials in a given place and period of time, and they change over the course of a group's engagement with social creativity;

2. some configurations are associated with greater expansion of space than others;

3. there are patterns in the flow between configurations; and

4. some patterns may be more generative of social creativity than others.

By flow, we mean the change in and order of configurations over time. Generativity in this context refers to the observable collective output.

Table 13.3 provides an overview of the configurations that took shape during all five sessions. It reveals that all the sessions started with Orientation. Sessions 3 and 4 showed the greatest similarity with the flow in Session 2, encompassing Expansion, Creation, and Exhibition. The flows in Sessions 1 and 5 were essentially the same, with a repetition of the Meeting Mode after a phase of Expansion.

A detailed comparison of the configurations in each session would exceed the scope of this chapter, but it is useful to consider some of the similarities and differences a bit more closely.

Table 13.3 Overview of the configurations in all the action experiments

\begin{tabular}{|c|c|c|c|c|c|}
\hline Time & $\begin{array}{l}\text { Basis of } \\
\text { comparison: } \\
\text { Session } 2\end{array}$ & Session 1 & Session 3 & Session 4 & Session 5 \\
\hline & Orientation & Orientation & Orientation & Orientation & Orientation \\
\hline & $\begin{array}{l}\text { Meeting } \\
\text { mode }\end{array}$ & Meeting mode & Expansion & Meeting mode & Meeting mode \\
\hline & Expansion & Expansion & Creation & Expansion & Expansion \\
\hline & Creation & Meeting mode & Exhibition & Creation & Meeting mode \\
\hline & Reflection & Reflection & (Reflection) & Exhibition & \\
\hline & Exhibition & & & Pseudocreation & \\
\hline & Rehearsal & & & & \\
\hline
\end{tabular}




\section{Orientation}

There were significant differences in the way the participants in the five sessions initially oriented themselves to the space. Whereas the Orientation configuration in Session 2 was characterized by huddling — with the participants remaining almost frozen in one spot for the whole time-the video recordings of Sessions 1, 3, and 5 show the people moving around and physically exploring the space.

\section{Meeting Mode}

In each case this configuration was initiated by someone suggesting that the participants sit or by someone bringing chairs out. The Meeting Mode seemed to be a way of reducing the size of the room and establishing a known set of behavioral rules in the undifferentiated space offered in the studio. We observed that once participants had positioned themselves in the Meeting Mode it was difficult for them to break out of that configuration and do anything besides talk. Only in Session 3 did no Meeting-Mode configuration come about.

\section{Expansion}

The Expansion configuration usually followed the Meeting Mode, but it formed in very different ways, took different amounts of time, and led to different configurations. In Session 1 Expansion began after participants had been in a Meeting Mode for over an hour. One of the participants stood up and began exploring the studio space by walking around and playing his musical instrument (a small mouth organ) at different points in the space. Researcher 1 joined in, using some of the furniture in the room for drumming. The other participants stood up, moved out of the circle of chairs, and observed what was happening. After a few minutes, however, the participants returned to the same circle of chairs, and the group appeared to revert to the Meeting Mode. There was no change in their position in the room or in their spatial relation to each other. Nor was there any sustained change in their use of the physical space. In Session 5 there was a brief Expansion when one of the participants got up from his chair and walked to the center of the room with Researcher 1 to illustrate how he would redesign the space. However, the other participants remained in their places, and everyone returned to the Meeting Mode after a few moments.

In Session 4 Expansion was quite lengthy, lasting approximately $45 \mathrm{~min}$. It began with a sudden burst of movement into singing, dancing, drumming, wandering around the room, and working with the art materials. For the most part the participants carried out these actions separately-each one doing his or her own thing. After about $2 \mathrm{~min}$ the participants began to reconfigure themselves, interacting with each other one-on-one or wandering around the room and looking at what others were doing. Gradually, they formed into a single group around paper and materials 
that the researchers had placed on the floor in the center of the room. The participants then shifted into the Creation configuration, talking around the paper and starting to use the art materials. In Session 3 the participants went directly from Orientation into Expansion-sitting on the floor and playing with materials as they talked.

\section{Creation Configuration}

Creation was characterized by the participants' trying out new ways of jointly acting and expressing thoughts and feelings that led to a collective outcome. It entailed the use of the art materials provided for the session but also the use of other objects in the room and the participants' own bodies (e.g., drumming on a board or whistling to make music). In Session 2 the work was a set of pictures; in Session 3 the participants painted, danced, hummed, whistled, and engaged in pantomime; and in Session 4 they made graffiti. The Creation configuration was generally characterized by a shift from talking to doing. In Sessions 2 and 3 there was little or, for stretches of time, even no talking during Creation. In Session 4 there was an interweaving of doing and talking. The intensity and length of the configuration varied, too: Creation in Session 2 was highly intense but relatively brief (10 min). In Session 3 it was both extremely intense and lengthy (36 min). In Session 4 it lasted for almost $35 \mathrm{~min}$, but at the end of that session the participants engaged in an activity that we designate as pseudocreation: They accepted the offer of one of the members to lead them in a Tai Chi exercise. Although it was a collective dance of a kind, it was highly ritualized, leaving the followers no scope for a creative response. We did not observe a Creation configuration in Sessions 1 and 5, whose participants never appeared to form as a group around a task other than talk and did not generate an observable product.

\section{Reflection}

The video recording shows evidence of Reflection in two of the sessions, and in both cases material played a focusing role. At the end of Session 1, the participants are seen holding and looking at a balloon on which the cameraman had written satisfaction, and they are talking while throwing it to each other. In Session 2 the participants leaned back to reflect together on their drawings. One of the factors that led us to give this configuration separate ontological status was that fact that its absence was conspicuous in Session 3, in which the participants had decided to communicate without speaking. The Creation configuration lasted to the end of the session, and there was no time for any other configuration. However, the participants felt such a strong need to reflect on the experience and talk about it that they spontaneously decided to meet for dinner later in the week. The experience of Creation without Reflection left the participants feeling as though something were unfinished. 


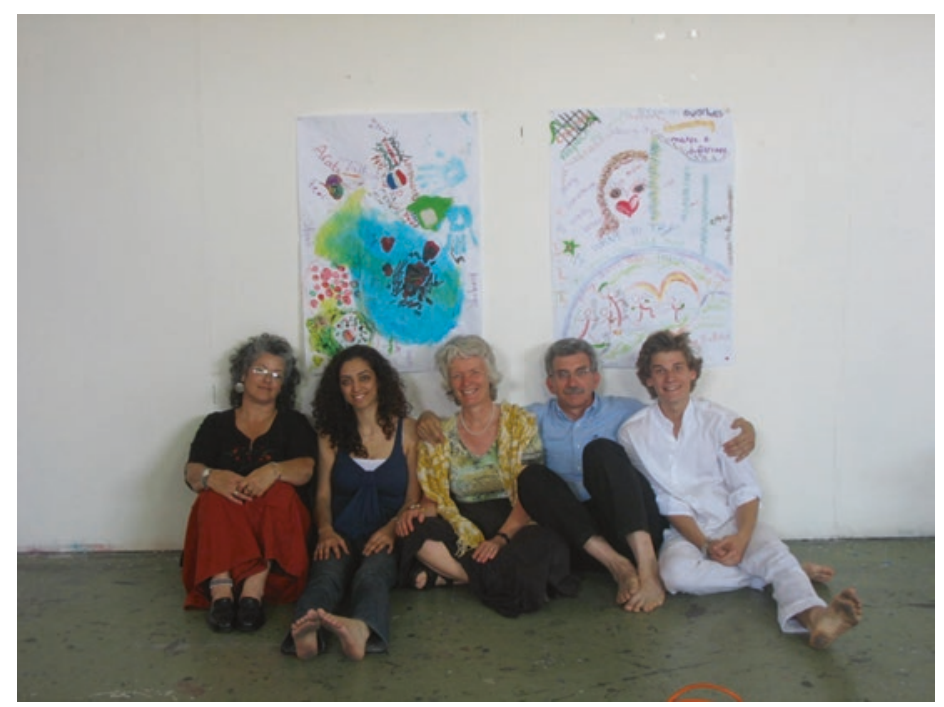

Fig. 13.9 Exhibition configuration, Session 3 of the action experiment in the Studio for Social Creativity (Photograph by the authors)

\section{Exhibition}

In three sessions the participants put their work on the wall, taking the creation out of the group's realm and displaying it as artists do. There were interesting differences worth noting. In Sessions 1 and 4 the participants became observers standing opposite the work, whereas in Session 3 the participants sat under their picture and took a group photograph, capturing themselves as part of the work that they had created (Fig. 13.9).

In Session 4 the Exhibition configuration formed when the participants hung their graffiti-like outputs of the Creation configuration onto the wall at the front of the room (see Fig. 13.10). Rather than transforming that part of the studio into a gallery space, it transformed it into a kind of public wall on which one might paint or spray graffiti messages for passers-by to see.

\section{Rehearsal}

In this configuration the participants expanded the space in order to include other people in a future session. Rehearsal was most evident in the video of Session 2, when the participants tried out ways of presenting their ideas for the intervention with the nursing students. In Session 4 the Rehearsal configuration took a different form. It was an attempt to mentally enact or envision what might happen rather than a physical acting out of a future event. The Exhibition of the graffiti on the studio wall presented the participants with a vision of what their messages could look like 


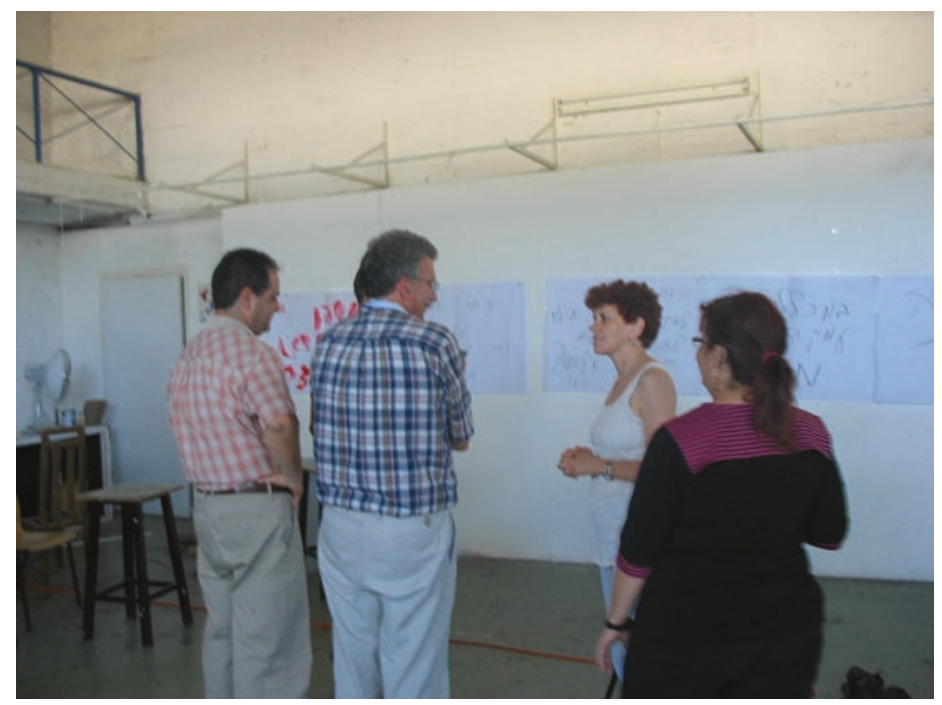

Fig. 13.10 Exhibition configuration, Session 4 of the action experiment in the Studio for Social Creativity (Photograph by the authors)

if displayed on walls of the college. The audio material captured a heated discussion about this scenario, revealing possible responses from students and the administration. During Rehearsal in Session 2, the participants set out the rules of behavior for themselves and the 60 nursing students, whereas Rehearsal in Session 4 involved the participants' self-projection into conditions where the rules of behavior were not under their control. In the end they decided not to pursue the idea of taking their work out of the studio.

\section{Discussion}

The goal of this chapter has been to deepen our understanding of the relationship between space and the generation of knowledge through and for action. The first thing we noticed from the analysis of the video recording was that the different groups varied widely in their use of the space, their interactions among each other, and their use of the materials. Furthermore, the groups' outputs - the ideas generated for using the space-differed significantly. The second striking outcome of our analysis was that commonalities existed across the sessions in terms of the knowledge-production processes. We identified seven distinct configurations: Orientation, Meeting Mode, Expansion, Creation, Reflection, Exhibition, and Rehearsal. These configurations differed in content, duration, and the transitions between them. However, their fundamental structural similarity allows us to formulate key insights into, or propositions about, the relationships between space, action, and knowledge generation. 


\section{Orientation in Undifferentiated Space}

As illustrated in the data analysis, every group began with the Orientation configuration. The participants took some time to become acquainted with the space and to figure out where and how to situate themselves so as to engage in the task. The Orientation configuration of each group differed significantly-some stood in one spot and looked around. Others walked around, exploring the room. We recognize that this behavior was at least in part a response to our opening suggestion that the participants explore the space for themselves. But our experience of this configuration, both in the actual moment and in subsequent observation of the video, has led us to conclude that it was also a reaction to uncertainty about what to do in this space and how to do it. Kornberger and Clegg (2004) wrote that space can be conceived of in two ways, namely, "as an absence of presence, as a vast emptiness, as something that one can get lost in ...[A]lternatively, it may be thought of socially" (p. 1095). By contrast, we suggest that, in practice, both conceptions can occur simultaneously because the physical and the social are interrelated in space. The participants entering the studio saw a vast emptiness, which led some to huddle along the wall, others to cluster close together elsewhere in the room. They perceived an absence of cues for positioning and behaving, and as a group they had no rules of their own yet for how to engage with each other in going about the task at hand in this new space.

The Orientation configuration led us to hypothesize that the uncertainty was the result of a particular relationship between features of the physical space and how the participants perceived and experienced them. The first feature was the undifferentiated character of the space. Kurt Lewin (1951/1997) introduced the construct of "differentiation" (pp. 218-220) to conceptualize learning as a change of sociopsychological space. In order to illustrate this notion, he drew an analogy to the process of finding one's way around an unfamiliar city without using a map. At first the city seems like a large undifferentiated mass, which a person experiences as uncertainty and in which one easily feels lost. Getting to know a city means mentally differentiating, or bounding off, distinct places and regions, seeing their location relative to other areas, and identifying ways of getting from one to another. Thus, the city becomes differentiated in the person's mind into distinct blocks, neighborhoods, and districts bounded by streets and other demarcations. Differentiation of a space also is at least partly about becoming aware of the rules governing behavior, such as knowing where one should not walk after dark.

For the participants in the experiment, the studio was, at first, highly undifferentiated, a characteristic that was influenced by both physical and social features. For them, it was a large, unfamiliar space as well as an encounter with people who came from different backgrounds and who had never worked together as a group before. Baldry (1999, p. 536) pointed out that physical environments as well as social factors (e.g., formal authority, gender) usually provide cues for behavior, so environmental cues reinforce what is socially defined as being appropriate or inappropriate. Both the structure of the room and semifixed aspects such as furniture and décor 
suggest what is to be done and how it should be done. To the extent that people have the prior knowledge to recognize these cues, they are likely to conform to expectations (p. 544). If we had brought the same people into a classroom, meeting room, or office, they would immediately have known where to sit and how to act because the space itself would have been perceived by the participants as full of clear cues about the rules of the game - that is, how to behave in this space. It is important to stress, however, that differentiation is not an intrinsic feature of the physical space itself but rather the way in which a person perceives that space and interacts with it.

\section{Orientation in Unencrusted Space}

The second feature that contributed to uncertainty is what we call unencrustedness of the space. By unencrustedness we mean that the room did not retain traces of the production of our previous sessions, that it was free of vestiges that might orient later groups in defining their task and shaping their expectations about the outcome. Unencrustedness was not a feature of the space itself but rather reflected an interaction between a decision of the convener-researchers, the physical space, and the participants. We had considered the option of leaving the products of previous groups' work in the room, of preserving changes they had made in the room's design, and/or of actually incorporating their suggestions for how the room should be used. Adopting any of those possibilities would have meant that each new group entering the studio would have been faced with evidence of the knowledge that had emerged from the previous group's engagement with the task. A group could have ignored this material or could have done something quite different, but it would still have been doing its work in the context of previous work and under its influence. Such an approach would have meant conceiving of the experiment as shaping the space through a cumulative, historical process in which each group, at least in part, interpreted and built on what earlier groups had done. We decided against this option because our guidelines called for leaving each group as much freedom as possible in determining how they would think and act in this space. Encrusting the space might have constrained the range of future possible ways of using the room. Of course, the space still had a history. Indeed, two of the participants remembered that the space had been an open stage, and its now closed structure saddened them.

\section{Qualifying Spaces of Possibility}

Our analysis confirms and extends work by scholars who have addressed the connection between space and possibility. Lewin (1951/1997, p. 268) suggested that undifferentiated space is not only full of uncertainty but full of possibilities. This assumption is also reflected in the work of contemporary scholars such as 
Kornberger and Clegg (2004), who argued that "space has to contain possibilities, which might be perceived as emptiness" (p. 1106) and that organizations need "chaotic, ambiguous and incomplete space" (p. 1106) in order to generate creative problem-solving. Other scholars, too, have suggested that "spaces of ambiguity" (Stark, 2009, p. 3) and "incomplete" work environments lend themselves to the kind of collaborative inquiry that is needed to deal with problems characterized by a lack of clarity and ambiguous information (Horgen, Joroff, Porter, \& Schön, 1999, p. 197). The implication is that the experience of undifferentiated space creates potential for producing new ways of thinking and acting. In an analysis of aesthetic experience with theater, Woodward and Ellison (2010) struck a similar note, describing it "as a space of imaginative elaboration, extension and perhaps even a space that afforded a type of 'reflexivity' in that it drew on existing structures as the basis for the realization of creative social action into the future" (p. 53).

The results of the experiment lead us to qualify these assumptions about undifferentiated space as spaces of possibility and to add the concept of unencrusted space. When faced with a space that generated uncertainty, almost all the groups went into the Meeting-Mode configuration. The participants sat and talked in a small circle, making no use of the open space of the room, of the artistic materials, or of other objects in the room. It appeared almost as though they created a room enclosed by invisible walls within the larger space. Thus, in a large room offering many possibilities in principle, people tended to reduce their uncertainty about how to engage with each other and the task by recreating a traditional kind of meeting space that utilized only a small fraction of the total space.

We hypothesize that the Meeting Mode provided participants with a sense of security and order in the face of uncertainty caused by a vaguely defined task and a large, strange, and undifferentiated space-and that the Meeting Mode exacts a price for this sense of security. Although we do not claim that the Meeting-Mode configuration necessarily prevents groups from thinking and acting creatively, our inference from the experiment is that the Meeting Mode is less likely to offer opportunities to experience surprise or newness. Once in the Meeting Mode, all the groups had a hard time breaking out of it and transitioning into what we called the Expansion configuration, and some of them never moved into Creation. We hypothesize that the Meeting-Mode configuration reflected a powerful norm or mental imprint that dictates how people come together to work at least in this particular organizational and cultural constellation. A theater or dance ensemble, like other groups from the art world, would most likely have perceived and used the space very differently. Future research could clarify whether mixed groups of participants who already have experience working together might be more experimental and playful than our participants were while working on a new task in the studio or whether their prior knowledge of how to work together would reduce the range of possibilities they could envision in the space. 


\section{Constructing Spaces Conducive to Newness}

Our research leads us to suggest that the experience of undifferentiated and unencrusted space offers a potential source of newness-if the participants use the opportunity. This view of the relationship between physical and social space is more accurate than a claim that undifferentiated and unencrusted spaces are spaces of possibility. We hypothesize that such space provides a context conducive to experiencing not knowing as an opening for creating new knowledge (Berthoin Antal, 2013). However, not knowing generates a sense of uncertainty that people (other than artists) tend to experience as uncomfortable. As a consequence, this experience of spaces confronts people with a choice in seeking to generate new knowledge: Do they impose a familiar set of rules onto the social and physical space, or do they engage the newness of the space to experiment with unfamiliar modes of being, thinking, and interacting with each other, the space, and objects in the space?

The qualified advantages of spaces of possibility and the phenomena of the Meeting Mode illustrate how space is constructed by people through interaction with the physical space, with objects, and among themselves. This fundamental point is often obscured in the literature when authors write about physical space as though it acted, almost with a will of its own, upon the people who interact with it, independently of their perception and choices. For example, Kornberger and Clegg (2004) asserted that "space is both the medium and outcome of the actions it recursively organizes" (p. 1106) and that "such spaces are capable of transforming themselves while being (ab)used and occupied by different people only temporarily" (p. 1106). These statements tend to anthropomorphize space, attributing to it an ability to "organize" or even "transform itself" and thereby opening the door to deterministic thinking. The findings of our experiment remind us that a space becomes generative or is transformed only through the agency of people who interact with the physical space and among themselves. Our analysis of the video recordings of the action experiments we conducted in the Studio for Social Creativity illustrates how physical space comes into human perception and is then acted upon and shaped by people, becoming a part of social space.

\section{The Relationship Between Talking and Doing ${ }^{6}$}

Another insight from the experiments concerns the relationship between talking and doing as media for innovative thinking and action. In designing the experiment, we hoped that the participants would go beyond verbal communication and do something with the room, the materials, and each other. Our inclination to favor action

\footnotetext{
${ }^{6} \mathrm{We}$ recognize that this duality is simplistic and even misleading because talk is also a form of action. We are using this formulation as a short form for purely cognitive verbal communication as distinct from multisensual ways of knowing, feeling, and expressing.
} 
over talk stemmed from the assumption that doing would heighten the aesthetic dimensions of experience by involving the body, the senses, and movement. We assumed that this intensification would enhance the innovative thinking of the participants and ultimately increase the creativity of outputs presented as a model of aesthetic relations "centered on exchanges of emotional energy which mark out moments of intersubjectivity between people" (Woodward \& Ellison, 2010, p. 52).

The familiar Meeting-Mode configuration favored talk and other engagement at the cognitive level. Even though some of this talk touched on highly interesting insights, our inference, based on our observations of the group members and our own subjective experience of this configuration, was that discussions in the Meeting Mode generated little energy. In Session 2, which we analyzed in depth, we could observe, and feel, the gradual, positive change in energy as the group moved out of the Meeting Mode into Expansion and then Creation. Our observation of the sessions revealed relationships between the engagement with objects and changes in energy levels. We confirm that "objects are manipulated and energized as products of the relations between the material, the sensual and the embodied as they play out in relation to imagination and the mind" (Woodward \& Ellison, 2010, p. 46). Our observations lead us beyond corroborating this claim; they bring us to suggest that by energizing objects, people energize themselves. The bodily experience of moving and shifting position in the process of working with the objects and art materials in the room stimulated and reinforced energy at both the individual and the group levels. The engagement of multiple bodily ways of knowing heightened the aesthetic dimensions of experience in ways that were energizing. We hypothesize that this energy made it easier for the participants to engage the uncertainty and explore new possibilities for thinking and action.

In our estimation the moment of highest energy and aesthetically most powerful experience occurred in the Creation configuration in Session 3. The participants chose to stop talking entirely. For approximately 45 min they used the artistic materials and their bodies, communicating through their eyes, movements, and touch. Ironically, the experience in this configuration led us to revise our thinking about the relative value of doing and talking. The nonverbal communication lasted until the end of the session, at which point all the participants expressed a strong need to talk about the experience. There was a sense of incompleteness without the opportunity for shared reflection. This experience led us to see talking and doing as two crucial moments whose interplay is critical in the creative process.

\section{Methodological Reflection}

In addition to the insights gained about the relationship between social and physical space and the generation of knowledge through and for action, we offer several methodological reflections from our experience with the action experiments in the Studio for Social Creativity. We confirm the value of separating visual from verbal analysis. It has permitted us to overcome the problem of most publications in this 
field: that "space has mainly been associated with the aural (auditory-oral) medium, emphasizing talking and listening, overlooking other salient bodily features such as seeing, looking, gazing, glancing, contemplating, scrutinizing, gesturing and moving in specific ways" (Edenius \& Yakhlef, 2007, p. 194). We benefited in at least three ways from the artistic presence of the Nose with the video camera. First, it was helpful to have an artist as part of our research team for a project that entailed exploring the possible contribution of artistic ways of knowing in social creation. He helped push us out of our comfort zone by posing questions before and after the sessions and by sharing his perspective on the experience. Second, the participants responded positively to his curious presence, reducing the camera to a playful instrument in all but one instance. ${ }^{7}$ Third, his inquisitive, energy-seeking approach revealed in the video material spaces of possibility the groups were not (yet) using. ${ }^{8}$

\section{Conclusion}

The analysis of our action experiments in the Studio for Social Creativity has permitted us to formulate propositions about the interaction between social and physical space. First, we invited people to envisage how to generate new possibilities (for interaction?) and then observed how these participants engaged with each other in the social and physical space provided for their task. On this basis we identified seven distinct configurations: Orientation, Meeting Mode, Expansion, Creation, Reflection, and Rehearsal. Second, by focusing on the video material, we revealed how anxious it makes people to be in what they perceive as undifferentiated space, how quickly they try to import rules from other spaces in order to reduce their uncertainty, and how they thereby risk getting locked into established ways of thinking and behaving. Third, the visual analysis also showed that shifting from one configuration to another involved expanding into new physical space (e.g., moving to the middle of room, working on the floor, or using the wall for exhibition) and engaging creatively with art materials and other objects. Adding aesthetic ways of experiencing and communicating increased the group's social creativity. Fourth, we postulate that both undifferentiated and unencrusted space are conducive for enabling the emergence of newness by maximizing the choice participants have as to how to engage with each other and their task. We thereby underscore and clarify the significance of space for creativity while avoiding the anthropomorphization of

\footnotetext{
${ }^{7}$ Although the Nose usually greeted the participants outside the studio, in one session he was perched on a ladder and holding the camera when the participants entered the room. One of those participants did not remember having been informed about the filming of the sessions, so he addressed what he felt to be an infringement. Recording stopped while the group discussed the situation. One of the participants commented "with a cameraman like that, nothing bad can happen," and they all agreed to the filming.

${ }^{8}$ Sometimes participants subsequently used the space to which the Nose had turned his attention (e.g., the balcony in Session 1). We do not know whether their actions were triggered by his, or whether he sensed something earlier that they discovered a little later.
} 
space, a conceptual trap that we encountered in the literature. Fifth, we note the need for movement between nonverbal and verbal forms of interaction in creating knowledge and sharing meaning. When people limit themselves to just talking, they tend to become stuck. Choosing not to talk during a phase of experimentation with bodily forms of knowing and communicating is generative; and verbal communication is needed once more for shared reflection.

The action experiments confirm how valuable it is for us as researchers to move out of our comfort zone when we are seeking new knowledge. We took two such steps in this project. First, we decided to participate in such an open exploratory process rather than stand back as observers or facilitators of a clearly structured workshop. Second, we chose in this chapter to focus our analysis solely on the visible evidence recorded on film. Both steps have proven highly generative. However, we recognize that the focus on the visible in our analysis did not give us access to certain important aspects. In order to explore the meaning the participants were giving to their actions, we need to listen to what they said and then connect that back to what we have observed. An analysis of the spoken words would enable us to correct or refine our configurations, for example. The other aspect we have not yet attended to are the power dynamics in the Studio for Social Creativity. Of course, they were present in the situation, for conflict in the region and tensions between groups at the college were two of the drivers for conducting the sessions in the studio. Moreover, there were differences in status among the participants (e.g., students vs. different levels of faculty; Palestinian Arab vs. Jewish backgrounds; men vs. women; and artists, academics, and practitioners). Exploring those dynamics in the construction of social space and use of physical space would require analyzing the spoken and written (e.g., graffiti) aspects along with the visible process.

Another issue that needs to be examined is the potential paradox inherent in the Studio for Social Creativity. We have posited that the undifferentiated and unencrusted nature of the space is an important condition for enabling participants to generate new ideas and ways of engaging there. How will its potential as a space of possibility be maintained for groups to return to over time? The more they use the space, the more likely it is that they will build mental models of how to use it (even if they leave it unencrusted), making it harder on their return for them to break out of an unusual way of having used it. We sense a need to engage more frequently and intimately with the world of the arts to stimulate our learning. Actors and musicians have experience with the paradox because they have to keep being creative on the stages they return to night after night. Fortunately, some artists are seeking inspiration precisely by moving out of the spaces they know in order to engage in learning creatively with people from other worlds, including academics (Berthoin Antal, 2015).

Acknowledgments We are grateful to the Institute for Advanced Study, Constance, for giving the first author the time and space to develop ideas for this chapter. 


\section{References}

Arieli, D., Friedman, V., \& Knyazev, G. (2012). Fostering cooperation while engaging conflict: An intercommunal case study. In J. Rothman (Ed.), From identity-based conflict to identity-based cooperation (pp. 135-156). New York: Springer.

Baldry, C. (1999). Space: The final frontier. Sociology, 33, 535-553. doi:10.1177/ S0038038599000346

Berthoin Antal, A. (2009). A research framework for evaluating the effects of artistic interventions in organizations. Gothenburg: TILLT Europe. Retrieved from http://www.wzb.eu/sites/default/ files/u30/researchreport.pdf

Berthoin Antal, A. (2012). Artistic intervention residencies and their intermediaries: A comparative analysis. Organizational Aesthetics, 1, 44-67. Retrieved from http://digitalcommons.wpi. edu/oa/vol1/iss $1 / 5$

Berthoin Antal, A. (2013). Art-based research for engaging not-knowing in organizations. Journal of Applied Arts and Health, 4, 67-76.

Berthoin Antal, A. (2014). When arts enter organizational spaces: Implications for organizational learning. In A. Berthoin Antal, P. Meusburger, \& L. Suarsana (Eds.), Learning organizations: Extending the field (pp. 177-201). Knowledge and Space: Vol. 6. Dordrecht: Springer. doi:10.1007/978-94-007-7220-5

Berthoin Antal, A. (2015). Sources of newness in organizations: Sand, oil, energy, and artists. In A. Berthoin Antal, M. Hutter, \& D. Stark (Eds.). Moments of Valuation: Exploring Sites of Dissonance (pp. 290-311). Oxford: Oxford University Press.

Berthoin Antal, A., \& Friedman, V. J. (2009, July 2-4). Spaces for social creativity: Integrating social entrepreneurship, conflict engagement and the arts. Paper presented at EGOS Annual Conference, Barcelona, unpublished manuscript.

Bourdieu, P. (1985). The social space and the genesis of groups. Theory and Society, 14, 723-744. doi:10.1007/BF00174048

Bourdieu, P. (1989). Social space and symbolic power. Sociological Theory, 7, 14-25. doi: $10.2307 / 202060$

Bourdieu, P. (1993). The field of cultural production. Cambridge: Polity Press.

Bourdieu, P. (1998). Practical reason: On the theory of action. Stanford: Stanford University Press.

Bourdieu, P., \& Wacquant, L. J. D. (1992). An invitation to reflexive sociology. Cambridge: Polity Press.

Brydon-Miller, M., Berthoin Antal, A., Friedman, V. J., \& Gayá Wicks, P. (2011). The changing landscape of arts and action research [Special issue on Arts and Action Research]. Action Research, 9, 3-11. doi:10.1177/1476750310396405

Cassirer, E. (1953). Substance and function and Einstein's theory of relativity (W. C. Swabey \& M. C. Swabey, Trans.). New York: Dover Press. (Original work published 1923)

Cassirer, E. (1944). An essay on man: An introduction to a philosophy of human culture. New Haven: Yale University Press.

Cassirer, E. (1961). The logic of the humanities (C. Smith Howe, Trans.). New Haven: Yale University Press.

Dewey, J. (2005). Art as experience. New York: Penguin. (Original work published 1934)

Edenius, M., \& Yakhlef, A. (2007). Space, vision and organizational learning: The interplay of incorporating and inscribing practices. Management Learning, 38, 193-210. doi: $10.1177 / 1350507607075775$

Ford, J., \& Harding, N. (2004). We went looking for an organization but could find only the metaphysics of its presence. Sociology, 38, 815-830. doi:10.1177/0038038504045866 
Friedman, V. J. (2011). Revisiting social space: Relational thinking about organizational change. In A. B. (Rami) Shani, R. W. Woodman, \& W. A. Pasmore (Eds.), Annual review of research in organizational change and development: Vol. 19. Research in Organizational Change and Development (pp. 233-257). Bingley: Emerald Group Publishing Limited. doi:10.1108/ S0897-3016(2011)0000019010

Friedman, V. J., \& Arieli, D. (2011). Building partnerships across cultures as negotiating reality. In H. S. Desivilya \& M. Palgi (Eds.), The paradox in partnership: The role of conflict in partnership-building (pp. 79-92). Bentham eBooks. doi:10.2174/9781608052 1101110101

Friedman, V. J., \& Desivilya, H. (2010). Integrating social entrepreneurship and conflict engagement for regional development in divided societies. Entrepreneurship and Regional Development, 22, 495-514. doi:10.1080/08985626.2010.488400

Friedman, V. J., \& Sharir, M. (2009). Mechanisms for supporting social entrepreneurship: A case study and analysis of the Israeli incubator. In J. Robinson, J. Mair, \& K. Hockerts (Eds.), International perspectives on social entrepreneurship (pp. 208-226). Basingstoke: Palgrave Macmillan.

Frye, N. (1964). The educated imagination. Bloomington: Indiana University Press.

Glaser, B. G., \& Strauss, A. L. (1967). The discovery of grounded theory: Strategies for qualitative research. Chicago: Aldine Publishing Company.

Hein, H. (1976). Aesthetic consciousness: The ground of political experience. The Journal of Aesthetics and Art Criticism, 35, 143-152. Retrieved from http://www.jstor.org/ stable/430372

Horgen, T. H., Joroff, M. L., Porter, W. L., \& Schön, D. A. (1999). Excellence by design: Transforming workplace and work practice. New York: John Wiley \& Sons.

Kornberger, M., \& Clegg, S. R. (2004). Bringing space back in: Organizing the generative building. Organization Studies, 25, 1095-1114. doi:10.1177/0170840604046312

Lefebvre, H. (1991). The production of space (D. Nicholson-Smith, Trans.). Oxford: Blackwell. (Original work published 1974)

Lehrer, J. (2007). Proust was a neuroscientist. New York: Houghton-Mifflin.

Lewin, K. (1936). Principles of topological psychology. New York: McGraw-Hill.

Lewin, K. (1997). Resolving social conflicts: Selected papers on group dynamics. In K. Lewin (Ed.), Resolving social conflicts and field theory in social science (pp. 1-152). Washington, DC: American Psychological Association. (Original work published 1948)

Lewin, K. (1997). Field theory in social science: Selected theoretical papers. In K. Lewin (Ed.), Resolving social conflicts and field theory in social science (pp. 155-422). Washington, DC: American Psychological Association. (Original work published 1951)

Linstead, S., \& Höpfl, H. (2000). Introduction. In S. Linstead \& H. Höpfl (Eds.), The aesthetics of organization (pp. 1-11). London: Sage.

McNiff, S. (1998). Trust the process: An artist's guide to letting go. Boston, MA: Shambhala.

Meusburger, P. (2009). Milieus of creativity: The role of places, environments, and spatial contexts. In P. Meusburger, J. Funke, \& E. Wunder (Eds.), Milieus of creativity: An interdisciplinary approach to spatiality of creativity (pp. 97-153). Knowledge and Space: Vol. 2. Dordrecht: Springer. doi:10.1007/978-1-4020-9877-2_7

Rapoport, A. (1982). The meaning of the built environment: A nonverbal communication approach. Beverly Hills: Sage.

Stark, D. (2009). The sense of dissonance: Accounts of worth in economic life. Princeton: Princeton University Press.

Strati, A. (2000). The aesthetic approach in organization studies. In S. Linstead \& H. Höpfl (Eds.), The aesthetics of organization (pp. 13-34). London: Sage. 
Taylor, S., \& Spicer, A. (2007). Time for space: A narrative review of research on organizational spaces. International Journal of Management Reviews, 9, 325-346. doi:10.1111/j.1468-2370.2007.00214.x

Woodward, I., \& Ellison, D. (2010). Aesthetic experience, transitional objects and the third space: The fusion of audience and aesthetic objects in the performing arts. Thesis Eleven, 103, 45-53. doi: $10.1177 / 0725513610381374$

Open Access This chapter is distributed under the terms of the Creative Commons Attribution 4.0 International License (http://creativecommons.org/licenses/by/4.0/), which permits use, duplication, adaptation, distribution and reproduction in any medium or format, as long as you give appropriate credit to the original author(s) and the source, provide a link to the Creative Commons license and indicate if changes were made.

The images or other third party material in this chapter are included in the work's Creative Commons license, unless indicated otherwise in the credit line; if such material is not included in the work's Creative Commons license and the respective action is not permitted by statutory regulation, users will need to obtain permission from the license holder to duplicate, adapt or reproduce the material. 